\title{
Veri Görselleştirmenin Bilgi Sistemlerinde Kullanımı: Web Tabanlı Mezun Bilgi Sistemi Örneği
}

\author{
Murat KILINÇa, b İlknur TEKEc
}

Özet

Son zamanlardaki veri bilimindeki yeni yaklaşımlar, verinin bilgiye dönüştürülmesi sürecindeki işleyişlerin hızlanmasını ve daha kesin sonuçlar ortaya çıkmasını sağlamıştır. Özellikle 2000'li yılların başından sonra yeni yaklaşımlar çerçevesinde, veri kavramının, gelişen teknolojiyle birlikte hayatımıza daha fazla uyumlu hale getirilmesinden sonra, büyük veri setleri ile anlamlı çıkarımlar yapmak daha kolay bir hale gelmiştir. Bu sayede hem yönetim kademelerinin işi kolaylaşmış hem de karar destek sistemlerinin daha da güçlenmesi sağlanmıştır. Bu kapsamda ortaya koyulan çalışma ile Manisa Celal Bayar Üniversitesi'ndeki yaklaşık 130.000 mezun verisi analiz edilerek sistem oluşturma aşamaları açıklanmıştır. Sonrasında ise analiz sürecinden geçen veri seti, belirli yazılım kütüphaneleri aracıllğıyla görselleştirilerek, anlamlı çıkarımların ortaya konulması amaçlanmıştır. Bu amaç doğrultusunda Mezun Bilgi Sistemi (MEBİS) geliştirilerek, veriye dayalı çıkarımların yapılabilmesi hedeflenmiştir.
Anahtar Kelimeler

Veri Analizi

Web Uygulamaları

Yönetim Bilişim Sistemleri

Makale Hakkında

Geliş Tarihi: 01.07.2019

Kabul Tarihi: 13.03.2020

Doi: 10.18026/cbayarsos.584804

\section{Use Of Data Visualization In Information Systems: Web Based Graduate Information System Example}

\begin{abstract}
Recently, new approaches in data science have accelerated the process of converting data into information and resulted in more precise results. Especially after the beginning of the 2000s, within the framework of new approaches, it has become easier to make meaningful inferences with large data sets after the data concept has been made more compatible with our life with developing technology. In this way, the work of the management levels has been simplified and the decision support systems have been strengthened. Within the scope of this study, the data of approximately 130.000 graduates at Manisa Celal Bayar University were analyzed and the system creation stages were explained. Afterwards, the data set, which has gone through the analysis process, is visualized through certain software libraries and it is aimed to reveal meaningful inferences. For this purpose, it is aimed that data based inferences can be made by developing the Alumni Information System (MEBIS).
\end{abstract}

Keywords

Data Analysis

Web Applications

Management Information

Systems

About Article

Received: 01.07.2019

Accepted: 13.03.2020

Doi: 10.18026/cbayarsos.584804

a İletişim Yazarı: kilinc.murat@cbu.edu.tr

b Bilişim Personeli, Manisa Celal Bayar Üniversitesi, ORCID: 0000-0003-4092-5967.

c Öğretim Görevlisi, Manisa Celal Bayar Üniversitesi, ORCID: 0000-0002-6383-4067. 


\section{Giriş}

Gelişen teknolojiyle birlikte bilgi çağı, beraberinde bilgi teknolojilerini de getirmiştir. Özellikle internetin yaygınlaşmasından sonraki süreç içerisinde bilgi teknolojilerinin hayatımızın neredeyse her alanına dâhil olması yadsınamaz bir gerçektir. Rekabet, hız, iletişim, analiz edebilme ve tüm süreçlerin takibi açısından bilgi sistemlerinin kullanımı bir gereklilik haline gelmiştir. Özellikle işletmeler hem kendilerini hem de çevrelerini daha iyi analiz edebilmek için, 2000'li yılların başlarından itibaren rekabet ortamında geriye düşmemek amacıyla bilgi sistemlerine tam olarak entegre olmuşlardır. Bu doğrultuda işletmelerdeki yönetim kademelerinin amaçlarına ulaşabilmek için bilgi teknolojilerini ve sosyal ağları sıklıkla tercih etmeleri durumu, dönüştürücü teknoloji içerisindeki en güzel örneklerden biridir (Laudon, 1999: 14). Dolayısıyla, bilişim ve iletişim döneminde teknoloji sayesinde bilgi üretimi oldukça önem kazanmıştır (Çukurçayır ve Çelebi, 2012: 61). Ancak bilgi teknolojileri sayesinde sunulan bu değişikliklere adapte olamamak işletmenin, hatta bazı durumlarda endüstrinin yok olması anlamına gelmektedir. Çünkü son yıllarda oldukça fazla iş alanı ortaya çıkmış ve önceki iş alanları da yıllar içinde değişime uğramıştır.

Yakın geçmişte ise birçok veriyi bünyesinde barındıran kurumlar da gelişen bilgi teknolojileriyle beraber işin içerisine dâhil olmuştur. Özellikle Türkiye'nin 2005 yılında kamu kurumlarında başlatmış olduğu e-dönüşüm ile beraber, kamu kurumlarındaki birçok işlemin yapılması kolaylaşmış ve daha kolay takip edilebilmesi sağlanmıştır. Diğer taraftan, "elektronik dönüşüm" kavramı üniversiteler boyutunda incelendiğinde, bilgi sistemlerinin gerekliliği günden güne önem kazanmıştır. Çünkü üniversite personelinin, öğrencilerin ve mezunların takip edilebilmesi ya da kişilerin işlerini daha kolay yapabilmesi için bilgi sistemlerine ihtiyaç vardır. Bu sebeple, ülkemizdeki tüm üniversiteler bu sistemleri farklı şekillerde kendi bünyeleri içerisinde kullanmaya başlamıştır. Dolayısıyla üniversite bilgi sistemleri, bütünleşik yapıda bir çözüm sağlayıcı olarak değerlendirilebilir ve bunu rektörlük birimleri, fakülte ve yüksekokul seviyelerinde gerçekleştiren sistemlerin genel adı olarak nitelendirilebilir (Kılıçaslan, Büyükabalı ve Aktener, 2002: 6). Bu tanımlama içerisindeki en temel yapı, geliştirilen uygulama ya da sistem her ne olursa olsun veri kavramına dayanmaktadır. Çünkü bu tarz sistemlerde tüm analizler, çıkarımlar, görselleştirmeler ve veri setleri sayesinde mümkün olmaktadır. Bu sebeple, veri kavramına dayanan sistemlerin mimarisi tasarlanmadan önce verinin nerelerde kullanılacağı önceden belirlenmeli ve sistem ona göre tasarlanmalıdır. Tasarım sürecinde veri görselleştirmenin nasıl oluşacağı da önemli bir noktadır. Veri görselleştirme, geliştirilen uygulamalarda uygulamayı kullanan kişi ya da kişilerin algılama yetenekleri ve kişiler arası yorumlama farklarını dikkate alan bir analiz gerçekleştirme olarak tanımlanabilir. Veri görselleştirme teknikleri sayesinde geliştirilen uygulamalar üzerinde etkili bir şekilde verinin portresinin çıkarılması mümkün olabilir ve bu doğrultuda genel bir çıkarıma varılabilir (Bilgin ve Çamurcu, 2008: 107). Analiz edilmesi zor olan veri setleri bile geliştirilen veri görselleştirme mekanizmaları ile desteklenerek daha iyi bir şekilde yorumlanabilir (Ghosh ve diğerleri, 2019: 347). Dolayısıyla veri görselleştirme, gözlem ve çıkarım vasıtasıyla karar verme sürecini büyük bir oran doğrultusunda geliştirebilir, harcanan zamanı azaltabilir ve veri analizi süreçlerinde katkı sağlayabilir (Wang ve diğerleri, 2015: 33).

Diğer bir önemli nokta ise tasarlanan veri mimarisi içerisinde verilerin güvende olup olmadığ konusudur. Çünkü artık günümüzde medya paylaşımları ve sosyal ă̆ gibi farklı 
kaynaklardan birçok veri seti üretilmekte ve bu üretilen miktar her geçen saniye katlanarak artmaktadır. Bu durum genel kapsamda bakıldığında, kişilerin mahremiyeti bakımından birçok zorluğa sebep olmuştur (Eyüpoğlu ve diğerleri, 2017: 177). Bu sebeple geliştirilecek sistemlerde kişisel verilerin mahremiyetinin özenle korunması ve veri paylaşımının kullanıcılardan izin alınmadığı sürece kesinlikle yapılmaması gerekir.

Bu çalışmada, Manisa Celal Bayar Üniversitesi bünyesinde bilgi teknolojileri kullanılarak, bulut sistem tabanlı bir mezun bilgi sistemi geliştirilmiştir. Araştırmada, büyük ölçüdeki mezun veri setleri, görselleştirilerek veri analiz süreci daha kolay bir hale getirilmiş ve sonuçları benzer uygulamalar incelenerek çalışma içerisinde tartışılmıştır. Ayrıca uygulama geliştirilirken 24 Mart 2016' da kabul edilen Kişisel Verilerin Korunma Kanunu da göz önünde bulundurularak kişilerin sadece kendi izinleri doğrultusunda veri paylaşımına olanak sağlanmıştır.

\section{Literatür Taraması}

Eyüpoğlu ve diğerlerinin (2017)'deki çalışmasında, büyük veri setlerinin korunması için gerekli olan araçlar, büyük veri sistemlerinin güvenliğinin sağlanmasındaki zorluklar, büyük çaptaki veri kaynaklarının neler olduğu ve veri güvenliği için geliştirilen yöntemler açılanıp tartışılarak, bu noktada kişisel verilerdeki mahremiyetin korunması için öneriler getirilmiştir. Bu korumanın yegâne sebeplerinden bir tanesi de büyük veri setlerinin ortaya çıışı ile birlikte geçmişte kullanılan klasik güvenlik tedbirlerinin yetersiz kalmasıdır. Bu yetersizliğin ortadan kaldırılması için literatürde var olan çalışmalar incelenerek özetlenmiş ve veri kavramındaki mahremiyetin korunması için çeşitli yöntemler gösterilmiştir.

Storey ve Song, (2017)'deki çalışmalarında büyük verinin yönetimini ele almış ve bu doğrultudaki gereklilikleri çalışmalarının içerisine eklemişlerdir. Bu kapsamda büyük veri kavramı, 5V olarak adlandırlan velocity, variety, volume, verasity, value kapsamında incelenmiş ve NoSQL'in de bulunduğu yeni teknolojiler incelenmiştir. Çalışmada en dikkat çekici noktalardan bir tanesi geleneksel olarak kullanılan ilişkisel veritabanlarının günümüzde her bakımdan yeterli olup olmadığı sorusudur. Çünkü klasik olarak günümüzde kullanılan ilişkisel veritabanları büyük miktardaki veriyi tutabilme ve işleyebilme konusunda hız, kapasite ve sorgulanabilme bakımından ilişkisel olmayan veri tabanlarına göre geride kalmaktadır. Bu bakımdan kullanımı oldukça yaygınlaşan ilişkisel olmayan veri tabanı kullanımının (NoSQL) hangi platformlarda kullanılabileceği makale içerisinde açıklanmıştır.

Gomes ve diğerlerinin (2013) yılında ortaya koydukları çalışmada, tıpkı bu çalışmada kullanılan Chartist ve JSMaps kütüphaneleri gibi Javascript ile derlenen bir kütüphane olan BioJS kütüphanesi kullanılmıştır. Biyolojik veriler genel kapsamda değerlendirildiklerinde, karmaşık ve heterojen bir yapıya sahip oldukları için analizleri, görsel hale getirilmeleri ve sonuçlarının aktarılması biraz daha zor olmaktadır. Çalışmaya göre BioJS bu noktada geliştirme ve paylaşım için güzel bir çerçeve sunmaktadır. Bu sebeple biyolojik verilerin kullanıldığı web sitelerinde genel geliştirme süresini azalttığından dolayı, BioJS araştırmacılar arasında bir tercih sebebi olarak görülmüştür. 
Fiorini ve diğerleri (2016)'daki çalışmalarında, deniz trafiğindeki sürekli artış ve deniz alanlarından istifade etme talebinin büyümesiyle artan veri trafiğiyle birlikte yüksek trafik hacimlerini yönetmek için denizler üzerindeki mekânsal verileri görselleştirerek analiz etmişlerdir. Aynı zamanda gerçekleştirdikleri bu analizin kullanım alanları açıklanarak çalışma içerisine eklenmiştir.

Wang ve diğerlerinin (2015) yılında yapmış oldukları çalışmada, büyük verinin analizinin büyük verideki veri boyutunu ve karmaşıklığını azaltarak bu doğrultuda kilit bir rol oynadığ açıklanmıştır. Çalışmada dikkat çeken detaylardan bir tanesi veri görselleştirmenin sağladığı faydaların yüzdesel olarak açıklanmasıdır. Buna göre veri görselleştirme; karar verme sürecini $\% 77$ oranında arttırmakta, zaman kaybını \%20 azaltmakta, daha iyi veri analizini \%43 oranında desteklemekte ve bilgi paylaşımını \%41 oranında daha fazla sağlamaktadır.

Joseph ve diğerleri (2010)'daki çalışmasında, bilişim teknolojileri endüstrisine devrim niteliğinde bir yenilik getiren bulut bilişim kavramı ele alınmıştır. Bu doğrultuda, bulut bilişimin detaylı olarak tanımı yapılmış, kavram karışıklıkları olmaması amacıyla terimler açıklanarak, bulut bilişimin geleceği, sağladığı fırsatlar ve önündeki engeller tartışılmıştır.

Srinivasan ve diğerlerinin (2019) yılında yapmış oldukları çalışmada, günümüzde artan veri kavramı için veri görselleştirmenin gerekli olduğundan bahsedilmiştir. Bu gereklilik sayesinde daha kolay bir şekilde çıkarım ve yorumlama yapıldığı belirtilen araştırmada, durumun ispatı için Voder adında bir uygulama geliştirilerek sonuçları tartışılarak incelenmiştir.

Fonseca ve diğerleri (2014) yılında yapılmış olan çalışmalarında, günümüzde geliştirilen çoğu web uygulamasının güvenliği etkileyen kritik hataları olduğu bu durumun büyük çaplı sistemlerde bile büyük güvenlik sorunlarının ortaya çıkmasına sebep olduğu belirtilmiştir. Bu tarz sorunları engelleyebilmek adına araştırmacılar daha önce sıklıkla yapılmış olan siber saldırı yöntemlerini anlamak gerektiğini ifade etmişlerdir. Bu doğrultuda da SQL Injection ve XSS gibi iki ana güvenlik açığını incelenerek çalışma içerisinde etkileri ortaya koyulmuştur.

Jacob 2016'daki çalışmasında, tasarlanan veri tabanındaki bütünlüğün ve güvenliğinin, öneminden bahsedilmiş ve bu doğrultudaki yaklaşımlar incelenerek çalışma içerisine dâhil edilmiştir. Araştırma MD5 ve HASH gibi kriptografik işlevlerin kullanımlarını içermektedir. Bu kapsamda MD5 kullanımındaki zorluklar açıklanarak aydınlatılmıştır. Çalışmada dikkat çeken en önemli husus, veri güvenliğinin bir örgütün sürekli başarısı ve gelişimi için oldukça gerekli olduğudur.

\section{Yöntem ve Teorik Çerçeve}

Tasarlanan sistemin hayata geçirilebilmesi için yöntem olarak "Yazılım Geliştirme - Yaşam Döngüsü" kullanılmış ve daha sonradan oluşabilecek sorun ya da problemlerin engellenebilmesi için bu döngü içerisindeki 7 adıma bağlı kalınmıştır. Çünkü sistematik yollarla geliştirilen uygulamalarda yazılım geliştirme yaşam döngüsünün etkili kullanımı oldukça büyük öneme sahiptir (Chauhan ve Saxena, 2013: 28). Bu 7 adım sırasıyla; problemlerin, fırsatların ve amaçların tanımlanması, bilgi gereksinimlerinin belirlenmesi, sistem ihtiyaçlarının analizi, önerilen sistemin tasarımı, yazılımın geliştirilmesi, sistemin test edilmesi ve sürdürülmesi, sistemin gerçekleştirilmesi ve değerlendirilmesi aşamalarından 
oluşmaktadır (Şekil 1). Ayrıca uygulamanın 6. ve 7. aşamaları “Bulgular” başlı̆̆ında değerlendirilmiştir.

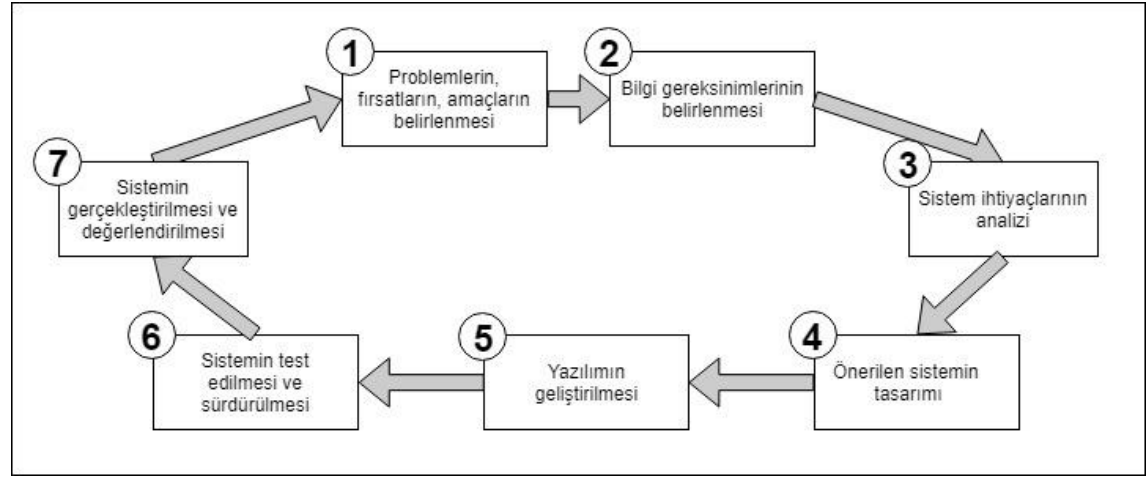

Şekil 1: Yazılım Geliştirme Yaşam Döngüsü

$\mathrm{Bu}$ aşamalardan ilk ikisi kapsamında diğer özel ve devlet üniversitelerinin mezun bilgi sistemleri incelenmiş mevcut problemler ya da yapılması gereken yeni özellikler değerlendirilerek analiz edilmiştir. Ayrıca sistem içerisinde olması gereken ve sistem geliştirildikten sonra temin edilecek olan bilgi gereksinimi de bu aşamalarda belirlenmiştir. Üçüncü aşamada yani sistem ihtiyaçlarının analizi kısmında ise bilgi gereksiniminin ortaya çıkaracağı sunucu gereksinimi, web trafiğinin sunucu bazında nasıl ayarlanacağı gibi konular ele alınmış ve ayrıca yazılım geliştirilirken hangi yazılım dilleri ya da kütüphanelerden faydalanılacağı belirlenmiştir. İhtiyaç analizinde en önemli hususlardan bir tanesi de verilerin güvenliği olduğundan dolayı özellikle kullanıcıların şifrelerinin güvenliğinin arttırılması noktasında, MD5 kriptografi yöntemi tercih edilmiştir (Jacob, 2016). Çünkü MD5 şifreleme tekniği, girilmiş olan karakteri-numarayı-yazıyı 35 haneden oluşan 128 bitlik tek bir numara dizisine çevirir. Güvenli olmasının nedeni 128 bite çevrildikten sonra geri çevrilememesidir. SHA1 şifreleme metodu ise MD5 ile aynı algoritmayı kullanan bir yapı ile karşımıza çıkmaktadır ve bu algoritmada da girilen değerler 40 karakterden oluşan 160 bitlik numara dizilerine çevrilir (Kessler, 2016). Ayrıca iki yöntemin iç içe kullanımı da söz konusudur. Bu bakımdan, duruma göre tercih sebebi olabilmektedir (Bkz. Tablo 1). Her iki şifreleme metodunun da kullanıldığı yere göre avantaj ve dezavantajları vardır. Manisa Celal Bayar Üniversitesi'nin Mezun Bilgi Sistemi - Mezun veri tabanında, daha güvenli olacağı düşünüldüğünden dolayı MD5 şifreleme metodu kullanılmıştır.

Tablo 1: Veri Şifreleme Yapısı

\begin{tabular}{ccc}
\hline Şifreleme Metodu & Örnek Şifre & Kriptografik Özet Fonksiyonu \\
\hline MD5 & password & 5f4dcc3b5aa765d61d8327deb882cf99 \\
\hline SHA1 & password & 5baa61e4c9b93f3f0682250b6cf8331b7ee68fd8 \\
\hline MD5 (SHA1) & password & 1619d7adc23f4f633f11014d2f22b7d8 \\
\hline SHA1 (MD5) & password & 55c3b5386c486feb662a0785f340938f518d 547f \\
\hline
\end{tabular}

MD5: Message-Digest Algorithm 5, SHA1: Secure Hashing Algorithm 1 
Dördüncü aşamada önerilen sistemin tasarımı gerçekleşmiştir. Sistem üzerinde düzgün bir veri analizi yapılabilmesi için bulut ortamı, kolay erişim için ise web ortamı tercih edilmiştir. Sistem tasarımındaki bulut ortamında; veri setlerinin birer çıkarım haline, daha sonrasındaki aşamalarda ise hedef ve strateji haline gelmesi amaçlanmıştır. İşleyiş içerisinde belirli veri setleri, birtakım kütüphaneler ile görselleştirilerek gözlem için hazır hale getirilir. Daha sonrasında ise her veri setinden oluşmuş olan gözlemler açıklanır ve yorumlanır. Bu açıklama ve yorumların hepsi bir araya geldiğinde ise veriye dayalı çıarım mekanizması ortaya çıar. Aynı şekilde çıkarımlar da bir araya gelerek bir sonraki aşamada hedeflerin ve stratejilerin belirlenmesini sağlayarak bir karar destek sistemi oluşturmaya başlar (Bkz. Şekil 2).

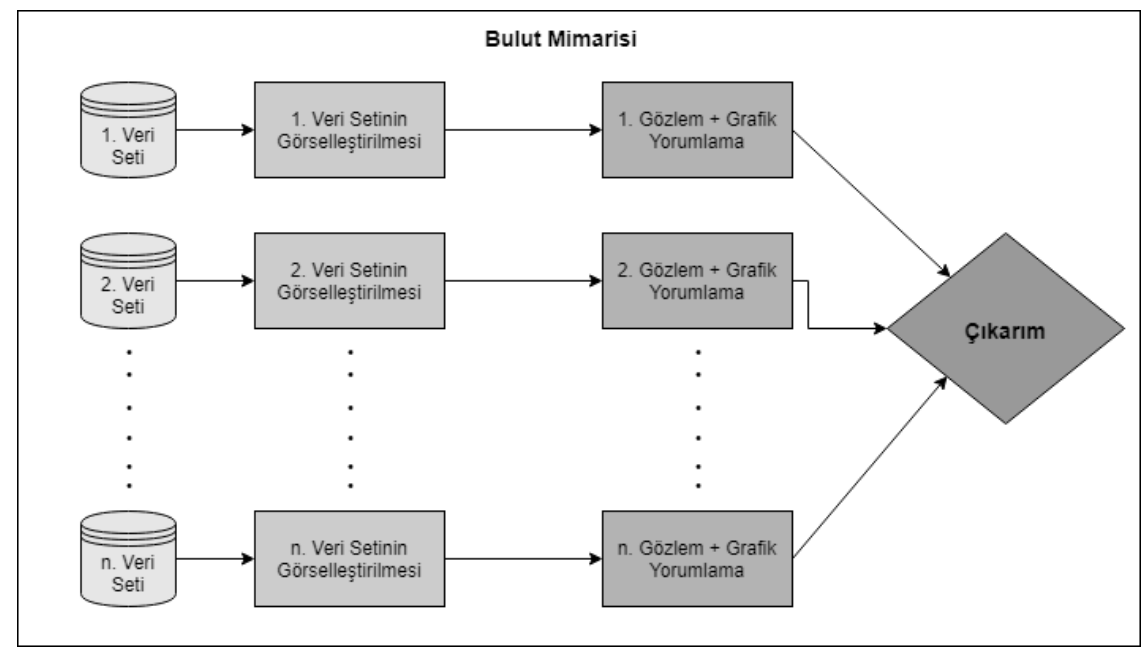

Şekil 2: MEBİS'in Bulut Mimarisi ve Veri Görselleştirme-Gözlem-Çıkarım Yapısı

\section{Yazılımın Geliştirilmesi ve Sürdürülmesi}

Veriye dayalı bir karar destek sisteminin oluşturulabilmesi, anlamlı sonuçların ortaya koyulabilmesi ve tanımlayıcı veri analizi yapılabilmesi için öncelikle mevcut veri setinin titizlikle analiz edilmesi gerekmektedir. Analiz sürecinden sonraki adımda yapılacak olan geliştirmenin düzenli bir şekilde uygulanabilmesi için işleyecek süreçler, görselleştirme süreçleri ve mantıksal-sorgusal süreçler olmak üzere ikiye ayrılmıştır (Bkz. Tablo 2). Gruplanan süreçler içerisinde yazılım geliştirme yaşam döngüsüne bağlı kalınmış olması, muhtemel bir problemde müdahaleyi kolaylaştırmaktadır. Daha sonra verilerin sisteme aktarılması için ilk olarak Üniversite Bilgi Sisteminde (UBS) tamamı mezun öğrencilerden oluşan yaklaşık olarak 130.000 kişilik excel tablosu, çeşitli normalizasyon süreçlerinden sonra MySQL Workbench veri tabanı yazılımına aktarılarak bir altyapı oluşturulmuştur. Oluşturulan altyapının kolay sorgulanabilmesi ve dinamik olması için ilişkisel yapıda bir veri tabanı tasarımı ortaya koyulmuştur. Bir sonraki aşamada ise veriler PHP programlama dili ile HTML/CSS/Bootstrap ile geliştirilmiş olan arayüz tarafına çekilerek çeşitli kriterlere göre Javascript ile derlenen Chartist kütüphanesi vasıtasıla görselleştirilmiştir. Bir diğer görselleştirme alanı olan mezun haritasında ise yine Javascript ile derlenen JSMaps kütüphanesi kullanılarak veri görselleştirmesi sağlanmıştır (Bkz. Tablo 4). 
Tablo 2: Sistem Bileşenleri ve Kullanım Amaçları Tablosu

\begin{tabular}{|c|c|c|}
\hline \multicolumn{3}{|c|}{ Kullanılan Yazılım, Programlama Dilleri ve Kütüphaneler } \\
\hline & $\begin{array}{c}\text { Yazılım/Programlama/ } \\
\text { Kütüphane }\end{array}$ & Kullanım Amacı \\
\hline \multirow{4}{*}{ 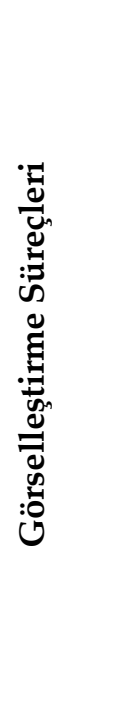 } & HTML/CSS/JavaScript & $\begin{array}{l}\text { Dinamik bir web ortamının oluşmasını sağlamak } \\
\text { için gerekli arayüzün tasarımını yapılması }\end{array}$ \\
\hline & Chartist Kütüphanesi & $\begin{array}{l}\text { Javascript ile derlenen kütüphane vasıtasıyla çeşitli } \\
\text { grafiklerin önceden belirlenmesi ve o grafiğe } \\
\text { uygun verilerin arayüz tarafına çekilerek } \\
\text { görselleştirilmesi }\end{array}$ \\
\hline & Bootstrap Kütüphanesi & $\begin{array}{l}\text { Responsive (Uyumlu ve esnek) bir tasarım } \\
\text { oluşturularak taşınabilir cihazlar ve bilgisayar } \\
\text { ortamlarında bozulmayan bir görüntü sağlanması }\end{array}$ \\
\hline & JSMaps Kütüphanesi & $\begin{array}{l}\text { Geliştirilen sistemin veri tabanındaki konum } \\
\text { verilerinin Türkiye haritası üzerinde gösteriminin } \\
\text { sağlanması }\end{array}$ \\
\hline \multirow{2}{*}{ 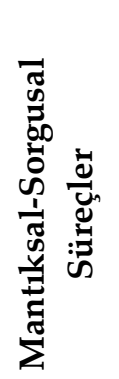 } & MySQL Workbench & $\begin{array}{l}\text { Çoklu veri kontrolüne uygun, ilişkisel veri } \\
\text { tabanının oluşturularak sorgulanabilir hale } \\
\text { getirilmesi }\end{array}$ \\
\hline & $\begin{array}{l}\text { PHP (Nesne Yönelimli Programlama } \\
\text { Dili) }\end{array}$ & $\begin{array}{l}\text { SQL ile veri tabanından çeşitli kriterler aracilığıyla } \\
\text { sorgulanan verilerin grafiklendirilmesi veya } \\
\text { listelenmesi için nesne tabanlı programlama yapısı } \\
\text { oluşturulması }\end{array}$ \\
\hline
\end{tabular}

Sistem içerisine entegrasyonu sağlanan verilerin, izleyeceği yol bir diyagram aracılığıyla önceden belirlenmiştir (Bkz. Şekil 3). Diyagrama göre, veriler öncelikle ilişkisel veri tabanında saklandıktan sonra SQL ile arayüz tarafına çekilmiştir. Daha sonrasındaki aşamada ise nesne tabanlı programlama dili olan PHP ile arayüz tarafına çekilen veriler derlenerek veri görselleştirme için uygun hale getirilmiştir. Bu doğrultuda nesne tabanlı programlama diliyle yorumlanan veriler, Javascript ile derlenen kütüphaneler aracılığıyla görselleştirilerek web uygulamasının arayüzü içerisinde konumlandırılmış ve çıarım yapmak için uygun bir hale getirilmiştir (Bkz. Şekil 3). Ayrıca görselleştirmeye destek olacak şekilde tasarlanan grafik altı yüzdesel dağlımlar için de gerekli olan formülüzasyonlar da önceden belirlenmiştir (Bkz. Tablo 5). 


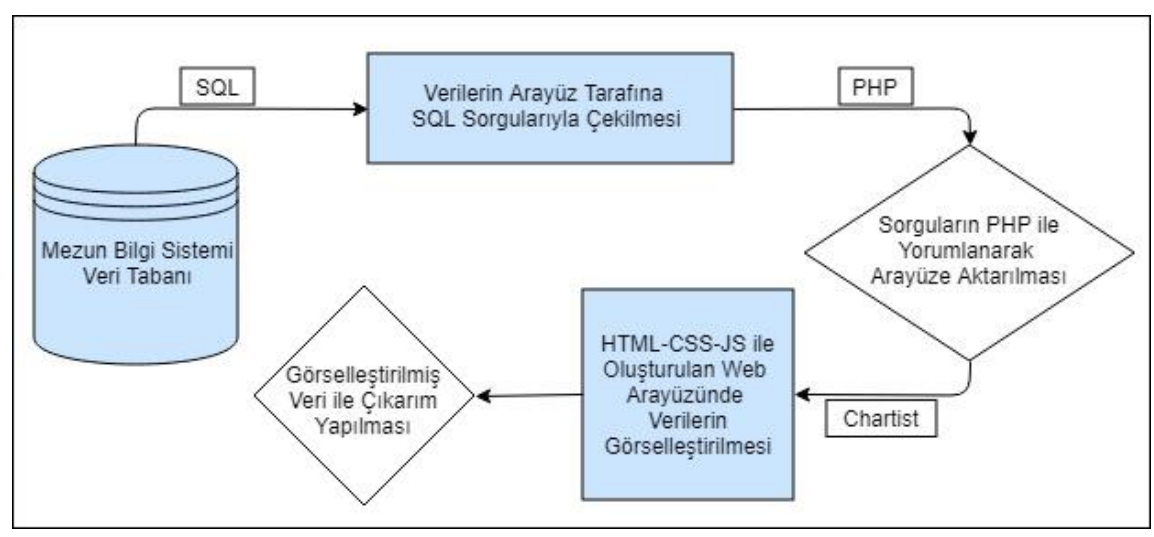

Şekil 3: Mezun Bilgi Sistemi Verilerin Akış Diyagramı

\section{Veri tabanı Yapisı}

Mezun bilgi sistemi veri tabanı hepsi ilişkisel olmak üzere toplamda 31 tablodan oluşmaktadır (Bkz. Şekil 4). Sistem içerisindeki veri yapısı, ilişkisel veri tabanı mantı̆̆ıyla daha kolay sorgulanabilir olduğu için NoSQL yerine ilişkisel veri tabanı modeli tercih edilmiştir.

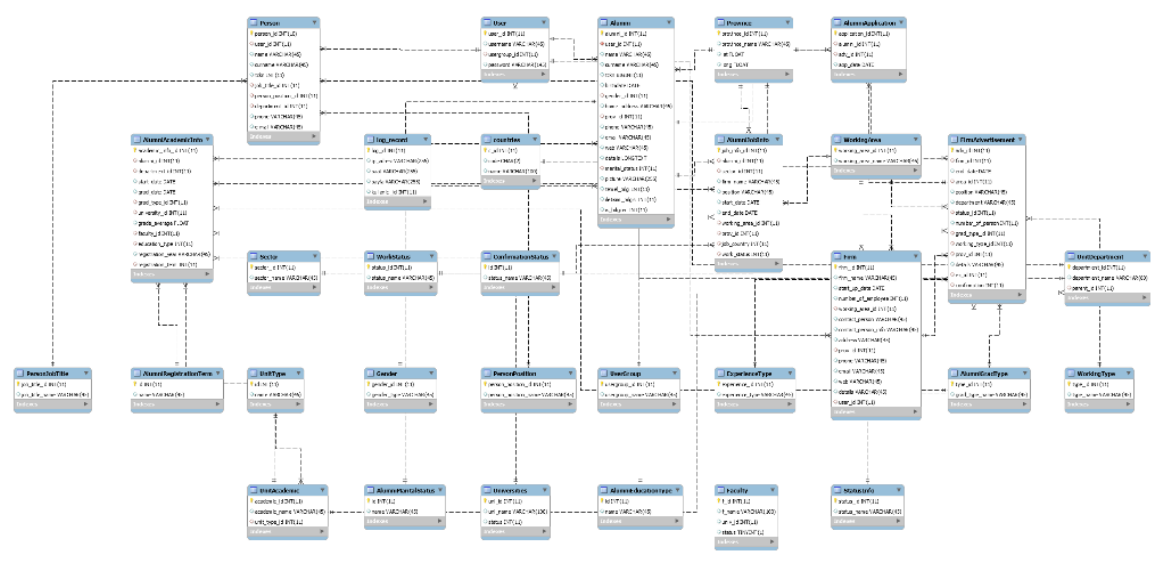

Şekil 4: Mezun Bilgi Sistemi İlişkisel Veri tabanı Yapısı

Ancak veri boyutu arttıkça NoSQL kullanımının performansı daha da arttıracağ 1 düşünülmektedir (Storey ve Song, 2017: 63-65). Diğer taraftan, mezunların sisteme girişi esnasında daha önceden oluşturulmuş “User (Kullanıı)” tablosu kullanılmaktadır. Bu tabloda mezunların T.C. kimlik numaraları ve doğum tarihleri baz alınarak giriş yapmaları sağlanmıştır. Bu doğrultuda kullanıcıların, sisteme giriş esnasında T.C. Kimlik numaraları ve doğum tarihleri aracılığıyla giriş yapması gerekmektedir. Güvenlik sebebiyle kullanıcıların sisteme ilk girişten sonra ayarlar sayfasına giderek şifrelerini güncellemeleri sistem tarafından ayrıca önerilmektedir.

Veri tabanının sorgulanmasıyla sağlanan veriler, görselleştirme ve veriye dayalı karar verme noktasında büyük önem taşıdığından dolayı, tablolar arası ilişkiler ve analiz kısmı gözetilerek hazırlanmıştır. Bu sayede veri tabanındaki veri miktarı artması arayüzdeki analiz süreçlerini, arkaplandaki yazılım süreçlerini olumsuz bir şekilde etkilememektedir. Ayrıca ölçeklenebilir 
bir yapı söz konusu olduğundan, veri yönetim sistemleri içerisindeki optmizasyon sorunları minimuma inmektedir (Luo ve diğerleri, 2018: 1).

\section{Bulgular ve Değerlendirme}

Yazılım geliştirme, yaşam döngüsünün 6. ve 7. adımları kapsamında sistemin test edilmesi ve sürdürülmesinin yanı sıra sistemin gerçekleştirilmesi ve değerlendirilmesi aşamaları sistematik bir şekilde bulgular başlı̆̆ 1 altında değerlendirilmiştir.

\section{Sistemin Gerçekleştirilmesi}

Geliştirilen uygulama 3 ayrı kullanıcı yapısına sahiptir. Bu kullanıcılar: mezun kullanıcısı, sistem yöneticisi ve firma kullanıcısı olarak sıralanabilir. Mantıksal olarak oluşturulmuş 3 kullanıcı yapısının 2 tanesi (mezun kullanıcısı ve sistem yöneticisi kullanıcısı) uygulama üzerinde aktif durumdadır. Kullanıcı yapıları oluşturulurken; bu kullanıcılara verilecek olan yetkiler hem diğer sistemlerin incelenmesiyle hem de sistem üzerinde geniş kapsamlı bir analiz yapılmasıyla belirlenmiştir. Bu doğrultuda, mezun kullanıcısı bazı bilgilerini güncelleyebilme, gizlilik ayarları ve veri paylaşımı konusunda izinleri verme yetkisine sahipken, sistem yöneticisi kimliğinde ise MEBíS üzerindeki tüm verileri kontrol edebilme yetkisi bulunmaktadır. Bu sayede, kullanıcı kimliklerine göre ayrışan web arayüzleri ile sistem daha kullanışlı bir hale gelmiştir (Shiokrin ve Carter, 2017: 1). Dolayısıyla, tasarlanan yetkilendirme yapısı sayesinde geliştirilen web uygulaması kullanıma hazır bir hale gelmiş ve gerçekleştirilmiştir.

\section{Sistemin Test Edilmesi ve Değerlendirilmesi}

Sistemin oluşturulma aşamasından sonra test aşaması sürecine girilmiştir. Test sürecinde, Google tarafından geliştirilen PageSpeed Insight/Lighthouse (Web Sitesi Test Arayüzü) aracı kullanılmıştır. Lighthouse, web sayfalarının kalitesini arttırmak için hizmet veren, açık kaynak kodlu otomatik bir araç olarak karşımıza çıkmaktadır. Bu ortamda yapılan testin sonuçları ele alındığında; performans kriterlerine göre süre analizleri "hızlı" kategorisinde sınıflandırılmıştır (Bkz. Tablo 3). Ayrıca 90-100 (hızlı), 50-89 (ortalama), 0-49 (yavaş) ölçeğinde hız skoru 91 olarak bulunmuş, geliştirilen uygulamanın hızlı kategorisinde olduğu doğrulanmıştır.

Tablo 3: Mevcut Sayfanın Mobil Ağ Kullanılarak Gerçekleştirilen Lighthouse Analizi

\begin{tabular}{cc}
\hline Performans Kriteri & Süre Analizi \\
\hline Tahmini Giriş Gecikmesi & $10 \mathrm{~ms}$ \\
\hline Etkileşim Süresi & $1.6 \mathrm{sn}$. \\
\hline Hız İndeksi & $1.6 \mathrm{sn}$. \\
\hline Illk CPU boşta & $1.4 \mathrm{sn}$. \\
\hline İlk Zengin İçerikli Boya & $0,7 \mathrm{sn}$. \\
\hline İlk Anlamlı Boya & $1,4 \mathrm{sn}$. \\
\hline
\end{tabular}

Ayrıca sistemin test edilmesinden sonraki süreçte ortaya çok büyük ağ yüklerinin önlenmesi, Javascript yürütme süresi, ana iş parçacığının çalışmasının en aza indirilmesi, metin 
sıkıştırmanın etkinleştirilmesi, CSS dosyalarının optimizasyonu, sunucu yanıt sürelerinin düşük tutulması, önemli isteklerin önceden yüklenmesi, kullanıcı zamanlaması işaretleri ve ölçüleri, gerekli kaynaklara önceden bağlanılması gibi kriterlerde de yapılan analizlerde geliştirilen uygulamanın başarılı denetimler aldığı görülmüştür (Bkz. Şekil 5). Bu denetimlerin başarıyla yerine getirilmesi web yazılımının kullanıcısı dostu bir yapıya sahip olduğunu göstermektedir.

\begin{tabular}{|c|c|c|c|}
\hline & Başarılı denetimler & 14 aud & idits ^ \\
\hline 1 & Ekran dışındaki resimleri ertele & & 0 - \\
\hline 2 & CSS'yi küçüultün & & $\bullet \vee$ \\
\hline 3 & JavaScripti küçült & $12 \mathrm{~KB}$ potansiyel tasarruf & $0 \vee$ \\
\hline 4 & Metin sıkıştırmayı etkinleştirin & & $0 \sim$ \\
\hline 5 & Gerekli kaynaklara önceden bağlan & & ○ $\vee$ \\
\hline 6 & Sunucu yanit süreleri düşük (TTFB) & Root dokümanı 180 ms sürdü & $0 \vee$ \\
\hline 7 & Birden çok sayfa yönlendirmesini önleyin & 190 ms potansiyel tasarruf & $0 \sim$ \\
\hline 8 & Önemli istekleri önceden yükleyin & & $\bullet \sim$ \\
\hline 9 & Animasyonlu içerik için video biçimleri kullanın & & $0 \sim$ \\
\hline 10 & Çok büyük ağ yüklerini önler & Toplam boyut: $2.291 \mathrm{~KB}$ & $0 \vee$ \\
\hline 11 & Așirı büyük bir DOM boyutunu önler & 188 düğümm & $0 \vee$ \\
\hline 12 & Kullanıcı Zamanlaması işaretleri ve ölçüleri & & ○ \\
\hline 13 & JavaScript yürütme süresi & $0,1 \mathrm{sn}$. & $0 \vee$ \\
\hline
\end{tabular}

Şekil 5: Test Sonrası Başarılı Denetimler Listesi

Yazılım geliştirmenin yaşam döngüsünün gereklilikleri yerine getirilerek oluşturulan sistemde, özellikle veri görselleştirme sayesinde veriler anlamlı bir hale gelerek, karar verme süreçlerine katkı sağlayacak bir duruma getirilmiştir. Dolayısıyla, geliştirilen bu web tabanlı mezun bilgi sistemini kullanan yönetim kademeleri, veri analizine dayalı çıkarımlarla gelecek senelerdeki eğitim-öğretim faaliyetlerini, üniversitenin yetiştirdiği öğrencilerin daha çok hangi sektöre yatkın olduğunu planlama noktasında daha etkin bir şekilde karar alabilirler. Bu doğrultuda, veri kullanımları ile gerçekleştirilen araştırma gündemlerinde, veriye dayalı karar verme süreçleri açıç̧a belirtilmiştir (Spillane, 2012: 134). 
Tablo 4: Veri Görselleştirme ve Analiz Tablosu

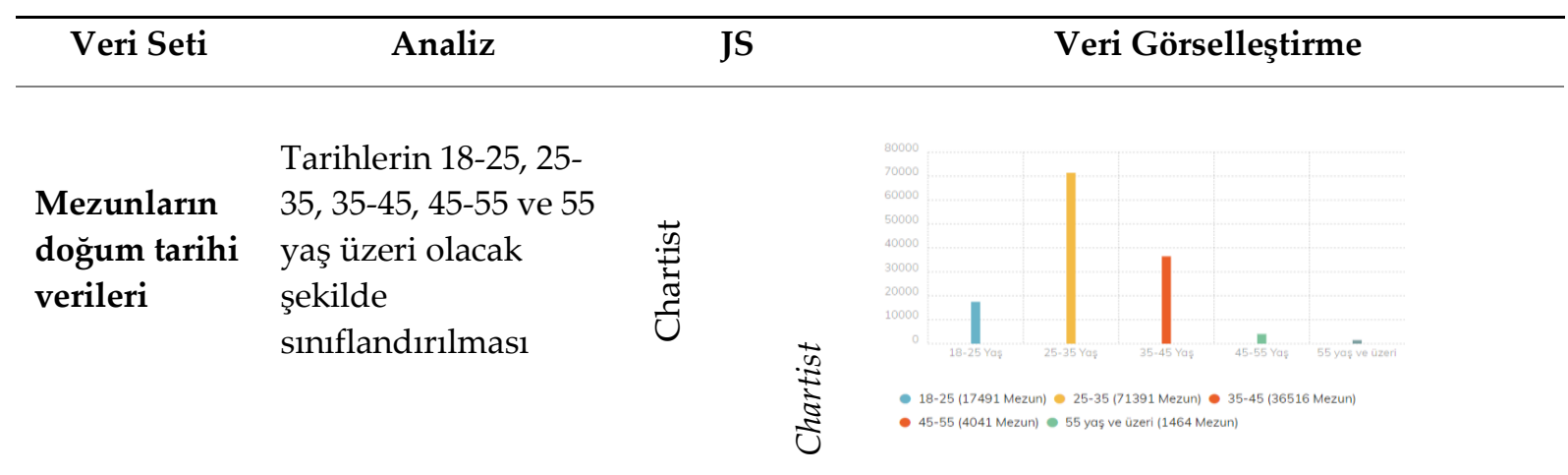

$\begin{array}{lll}\text { Mezunların } & \text { Mezuniyet } \\ \text { mezuniyet } & \text { tarihlerine göre veri } \\ \text { tarihi verileri } & \text { tabanından sayım } & \text { yapılarak arayüze }\end{array}$

aktarılması

$\begin{array}{ll}\text { Mezunların } & \text { Veri tabanındaki her } \\ \text { mezuniyet } & \text { mezunun mezuniyet } \\ \text { türürünün SQrileri } & \begin{array}{l}\text { sorgulanarak } \\ \text { arayüze aktarılması }\end{array}\end{array}$

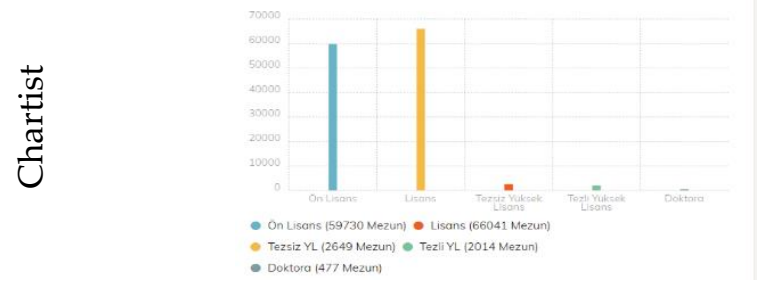

Mezunların Öğrenim türü öğrenim türü verilerinin 3 ayrı verileri siniflandirmayla sorgulanip arayüz tarafına çekilmesi

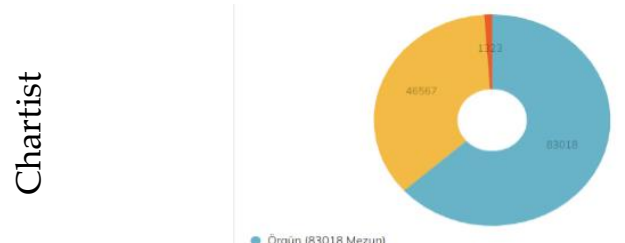

$\begin{array}{ll}\text { Mezunların } & \begin{array}{l}\text { Mezunların konum } \\ \text { verilerinden yola }\end{array} \\ \text { konum } & \text { çıarak JSMaps } \\ \text { verileri } & \text { kütüphanesi ile } \\ & \text { arayüze aktarılması }\end{array}$

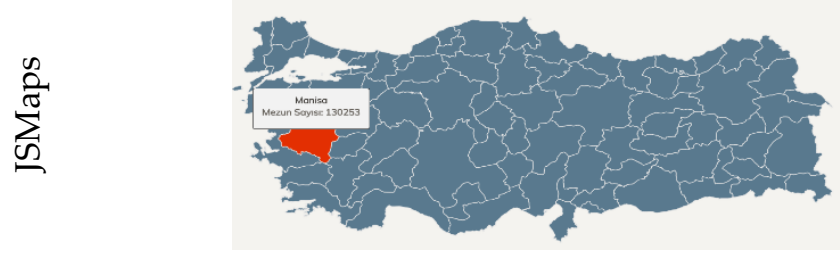


Tablo 5: Veri Yüzdesel Dağılım Analizinin Örnek İşlem Yapısı ve Web Ortamına Aktarımı

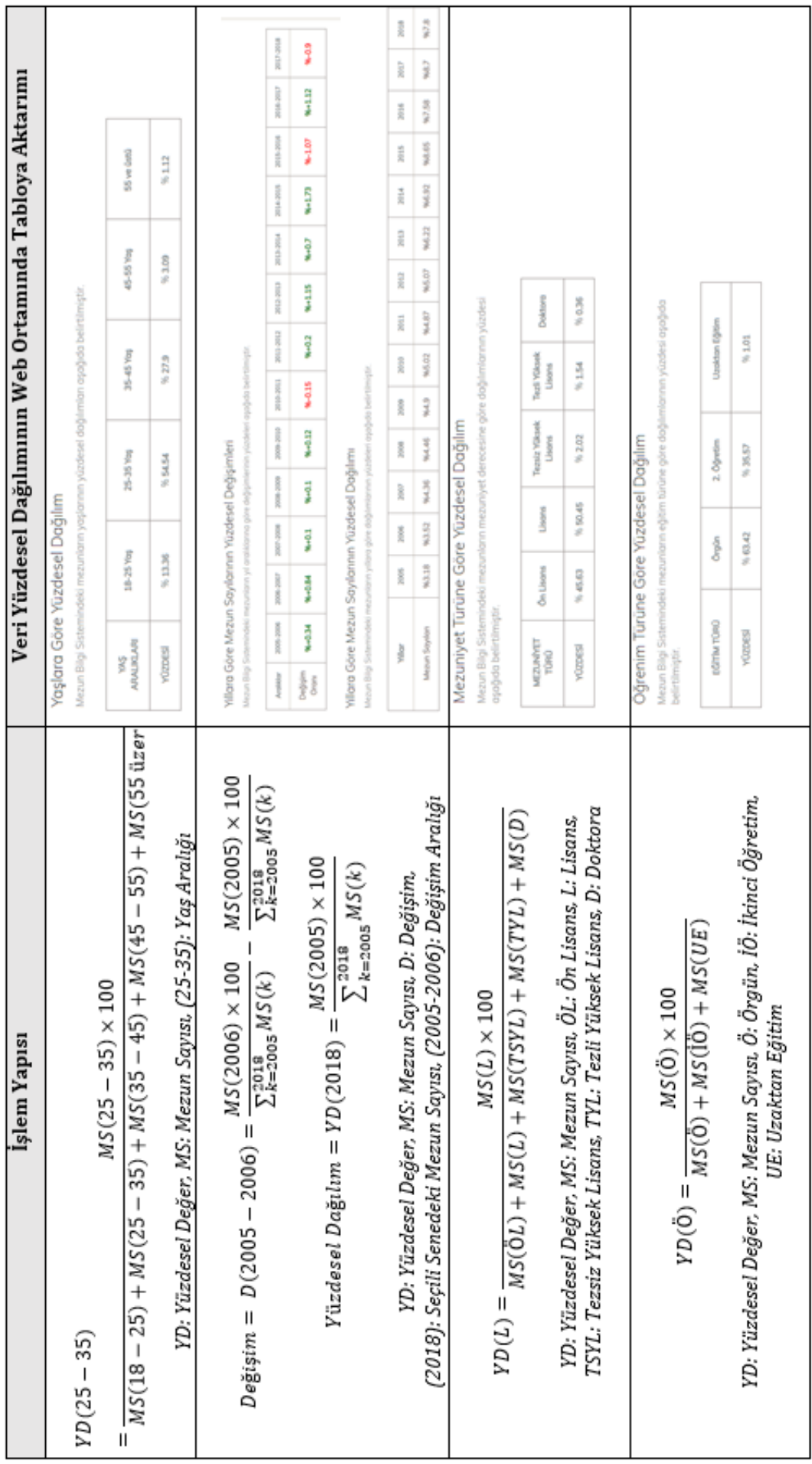

\section{Sonuç}


Sonuç olarak, kurumlardaki bilgi sistemlerinin gerekliliği, son 10 yıldır kendini iyiden iyiye hissettirmektedir. Öyle ki günümüzde bir kamu ya da özel kurumun başarısı, bilgi sistemlerini kullanmasıyla doğru orantılı bir şekilde ilerlemektedir. Diğer taraftan günümüzün trendi olan veri kavramının miktarındaki artış çok büyük ölçüde olduğu için, bu verilerin düzenli bir şekilde tutularak analiz edilmesi, çıkarım yapılması ya da raporlanması süreçleri, bu doğrultuda geliştirilen bilgi sistemleri ile mümkün olmaktadır. Manisa Celal Bayar Üniversitesi de bu noktada mezunları için bilgi sistemlerini daha da geliştirerek diğer sistemlerle uyumlu hale getirme yoluna gitmiştir. Üniversiteler bazında değerlendirildiğinde; geliştirilen bilgi sistemleri sayesinde, hem mezunlar ile yapılacak etkinliklerin bir sistem üzerinden kontrol edilmesi sağlanmış, hem de kişisel verilerin korunması kanunu göz önüne alınarak mezunların eğitim ve iş hayatıyla ilgili verileri kendi hesaplarına girmesi, sistemin daha da iyi raporlama yapabilmesini sağlamıştır. Sistemdeki bu veri analizi, raporlama süreçleri sayesinde, mezunların iş bulma oranı saptanarak genel bir çıkarım yapılabileceği gibi fakülte ya da bölüm bazında istatistikler elde edilerek yorumlanabilir, bu sonuçlara yönelik eylem planları gerçekleştirilebilir. Tüm bu süreçler, çeşitli kriterlerle birlikte üniversitenin "kalite" anlamında değerlendirilmesinde önemli rol oynamaktadır. Dolayısıyla, bilgi teknolojileri ile geliştirilen mezun bilgi sistemlerinin tüm üniversitelerde hayata geçerek analiz ve raporlama süreçlerini iyileştirmesi gerekmektedir. Bu alanda yapılan çalışmaların giderek artması da konunun ne kadar önem kazanacağının göstergesidir.

\section{Öneriler}

Mezun bilgi sisteminin daha iyi bir şekilde diğer sistemlere entegre olmasını sağlamak amacıyla servis altyapısı oluşturulması hem sistemin veri güvenliğini daha da arttıracak, hem de optimizasyon süreçlerini hızlandıracaktır. Bu sayede diğer bilgi teknolojilerinden manuel olarak sağlanan veri modeli, yerini bütünleşme modeline bırakacaktır. Öğrenci mezun olduğunda diğer bilgi teknolojilerindeki mezun olma durumu sistem tarafından tespit edilebilecek ve öğrenci kimliği, mezun kimliğine dönüşerek sistem içerisindeki yerini alabilecektir. Öneriler arasındaki diğer bir kısım ise mezunların kariyer alanındaki geliştirmeler olarak düşünülmüştür. Bu geliştirme ile sisteme iş ilanı vermek isteyen şirketler dâhil edildikten sonra mezunlar için bir kariyer ortamı oluşturulabilir. Bu sayede, mezunların iş bulma ve kariyer planlaması konusundaki bir diğer alternatifinin üniversite mezun bilgi sistemi olması sağlanabilecektir.

\section{Kaynakça}

Eyüpoğlu, C., Aydın, M. A., Sertbaş, A., Zaim, A. H., \& Öneş, O. (2017). Büyük Veride Kişi Mahremiyetinin Korunması. Bilişim Teknolojileri Dergisi, 10(2), 177-184.

Kılıçarslan, H., Büyükabalı, S., \& Aktener, N. (2002). Üniversite Bilgi Sisteminde İnternet Uygulamaları Deneyimleri. Akademik Bilişim, 6-8.

Ghosh, S., Datta, A., Tan, K., \& Choi, H. (2018). Slide-A Web-Based Tool For Interactive Visualization Of Large-Scale-Omics Data. Bioinformatics, 35(2), 346-348.

Laudon, K. C., \& Laudon, J. P. (1999). Management Information Systems. Prentice Hall Ptr. 
Gómez, J., García, L. J., Salazar, G. A., Villaveces, J., Gore, S., García, A., ... \& Dumousseau, M. (2013). Biojs: An Open Source Javascript Framework For Biological Data Visualization. Bioinformatics, 29(8), 1103-1104.

Bilgin, T. T., \& Çamurcu, A. Y. (2008). Çok Boyutlu Veri Görselleştirme Teknikleri. Akademik Bilişim, 30, 107-112.

Storey, V. C., \& Song, I. Y. (2017). Big Data Technologies And Management: What Conceptual Modeling Can Do. Data \& Knowledge Engineering, 108, 50-67.

Fiorini, M., Capata, A., \& Bloisi, D. D. (2016). A1s Data Visualization For Maritime Spatial Planning (Msp). International Journal of E-Navigation And Maritime Economy, 5, 45-60.

Joseph, A. D., Katz, R., Konwinski, A., Gunho, L. E. E., Patterson, D., \& Rabkin, A. (2010). A View of Cloud Computing. Communications Of The Acm, 53(4).

Srinivasan, A., Drucker, S. M., Endert, A., \& Stasko, J. (2019). Augmenting Visualizations With Interactive Data Facts To Facilitate Interpretation And Communication. IEEE Transactions On Visualization And Computer Graphics, 25(1), 672-681.

Fonseca, J., Seixas, N., Vieira, M., \& Madeira, H. (2014). Analysis Of Field Data On Web Security Vulnerabilities. IEEE Transactions On Dependable And Secure Computing, 11(2), 89-100.

Jacob, N. M. (2016). Vulnerability Of Data Security Using Md5 Function in Php Database Design. International Journal Of Science And Engineering (Ijse).

Mevzuat Bilgi Sistemi, "Kişisel Verilerin Korunması Kanunu(Https://Www.Mevzuat.Gov.Tr/Mevzuatmetin/1.5.6698.Pdf), (09.01.2019)

Wang, L., Wang, G., \& Alexander, C. A. (2015). Big Data And Visualization: Methods, Challenges and Technology Progress. Digital Technologies, 1(1), 33-38.

Kessler, G. C. (2016). The Impact Of Md5 File Hash Collisions On Digital Forensic Imaging. Journal Of Digital Forensics, Security And Law, 11(4), 9.

Çukurçayır, M. A., \& Çelebi, E. (2012). Bilgi Toplumu Ve E-Devletleşme Sürecinde Türkiye. Uluslararası Yönetim İktisat Ve İşletme Dergisi, 5(9), 59-82.

Pagespeed Insight, "Web Pages Fast Test On All Devices (Https://Developers.Google.Com/Speed/Pagespeed/Insights/), (24.12.2018)

Chauhan, N. S., \& Saxena, A. (2013). A Green Software Development Life Cycle For Cloud Computing. It Professional, 15(1), 28-34.

Luo, S., Gao, Z., Gubanov, M., Perez, L. L., \& Jermaine, C. (2018). Scalable Linear Algebra On A Relational Database System. IEEE Transactions On Knowledge And Data Engineering.

Spillane, J. P. (2012). Data in Practice: Conceptualizing The Data-Based Decision-Making Phenomena. American Journal Of Education, 118(2), 113-141.

Shokhrin, A., \& Carter, K. D. (2017). Methods, Systems, And Computer Readable Media For Authorization Frameworks For Web-Based Applications. U.S. Patent No. 9,591,000. Washington, Dc: U.S. Patent And Trademark Office. 